\title{
PEMANFAATAN APLIKASI CUSTOMER RELATION MANAGEMENT PADA KOPERASI
}

\author{
Samuel Manurung ${ }^{1}$, Mufria J. Purba ${ }^{2}$ \\ ${ }^{1}$ Fakultas Ilmu Komputer, Teknik Informatika, Universitas Methodist Indonesia \\ ${ }^{2}$ Fakultas Ekonomi, Komputerisasi Akuntansi, Universitas Methodist Indonesia \\ E-mail : samuelvanbastenmanurung070189@gmail.com
}

\begin{abstract}
ABSTRAK
Koperasi biasa disebut sebagai sarana untuk membantu masyarakat dari kalangan ekonomi yang rendah sampai keadaan ekonomi ke atas. Dengan adanya unit untuk simpan pinjam dapat membantu masyarakat di daerah kabanjahe membuka suatu usaha di dalam meningkatkan perekonomian masyarakat di kabanjahe. Pembayaran tagihan oleh nasabah dan event - event yang ingin dilakukan dari koperasi tidak pernah sampai dikarenakan kurangnya informasi yang diterima oleh nasabah. Oleh karena itu dibutuhkan suatu sistem yang sangat membantu di dalam proses event - event yang mendukung di dalam koperasi. Adapun aplikasi CRM (Customer Relation Managemen) ini dapat membantu di dalam proses pemberitahuan dan mempermudah di dalam proses transaksi pembayaran koperasi. Penelitian yang dilakukan ini dapat mempermudah pihak koperasi dan anggota koperasi di dalam melakukan transaksi dan sangat membantu juga terhadap nasabah di dalam proses notifikasi dari event event kegiatan koperasi serta tagihan nasabah serta notifikasi diberikan 3 hari sebelum kegiatan atau event dari CU.
\end{abstract}

.Kata kunci: Aplikasi, $C R M$, koperasi, notifikasi, transaksi

\begin{abstract}
Cooperatives are usually referred to as a means to help people from low economic circles up to economic conditions upwards. With the existence of a unit for savings and loans can help the community in the district of Kabanjahe open a business in improving the economy of the people in Kabanjahe. Payment of invoices by customers and events to be carried out by cooperatives never arrive due to a lack of information received by customers. Therefore we need a system that is very helpful in the process of supporting events in the cooperative. The CRM (Customer Relationship Management) application can assist in the notification process and simplify the cooperative payment transaction process. This research can facilitate the cooperatives and cooperative members in conducting transactions and is very helpful also to customers in the notification process of cooperative activities and customer bills and notifications are given 3 days before the activities or events from $C U$.
\end{abstract}

Keywords: Aplication, Cooperative, CRM, Notifications, transactions

Author Korespondensi (Samuel Manurung)

Email : samuelvanbastenmanurung070189@gmail.com

\section{PENDAHULUAN}

Dalam kamus bahasa inggris, kata koperasi yaitu cooperative ataupun bisa juga dibilang dengan co-opertaion. Dimana dari kata koperasi diambil kesimpulan suatu sifat yang saling bekerja sama, saling bahu membahu, ataupun bisa juga dibilang saling tolong menolong di dalam melakukan usaha. Dengan kata lain bahwa Koperasi ini bertujuan utuk meningkatkan taraf hidup anggotanya dan masyarakat sekitarnya, membantu kehidupan para anggota koperasi terutama dalam bidang ekonomi, membantu pemerintah di dalam mewujudkan anggota ataupun masyarakat yang seimbang dan sejahtera, dan berperan sebagai membangun sistem perekonomian yang secara nasional [2].

Di dalam kehidupan sehari - hari sangat dibutuhkan koperasi sebagai unit untuk membantu di dalam memenuhi kebutuhan masyarakat umum dan terutama masyarakat kecil dan sederhana. Ketika masyarakat membutuhkan dana di dalam kehidupan sehari - hari koperasi sangat cocok apabila di dalam sesuatu hal yang kita inginkan diharuskan dibayar kontan terutama di dalam membuka suatu usaha di daerah kabanjahe. 
Customer relation management secara sosial merupakan bagian dari penggunaan data mining sesuai dengan gambaran atau teknik yang dilakukan. Di dalam memberikan partisipasi dibutuhkan suatu model baik dari internet berupa website, blogger, dan situs yang mengandung sebuah informasi untuk pengembangan dari sistem Customer relation management pada sentris secara otomatis yang kaitannnya terhadap klien.[1]

\section{Konsep Customer Relationship} Management (CRM) dapat dipahami dalam tiga tataran, yaitu strategis, operasional, dan analitis. CRM strategis terfokus pada upaya untuk mengembangkan kultur usaha yang berorientasi pada pelanggan atau customer-centric. Kultur ini ditujukan untuk merebut hati konsumen dan menjaga loyalitas mereka dengan menciptakan serta memberikan nilai bagi pelanggan yang mengungguli para pesaing. Kultur ini tercermin dari perilaku pucuk pimpinan perusahaan, desain sistem formal di dalam perusahaan, dan berbagai mitos dan cerita yang beredar di dalam perusahaan.CRM operasional lebih terfokus pada otomatisasi cara-cara perusahaan dalam berhubungan dengan pelanggan. Berbagai aplikasi perangkat lunak CRM memungkinkan fungsifungsi pemasaran, penjualan, dan penjualan dapat berjalan secara otomatis. CRM analitis digunakan untuk mengekploitasi data konsumen demi meningkatkan nilai mereka (dan nilai perusahaan).

CRM pada dengan cara di dalam penyampaian informasi terhadap anggota yang berlangganan sebagai bahan pemberitahuan tentang produk dan lainya serta dapat memberikan sebuha komentar dan pendapat, oleh karena itu owner dapat memeriksa laporan - laporan yang berkaitan untuk kebutuhan instansi [12]

Dalam rangka meringankan beban masyarakat di daerah kabanjahe, maka dibutuhkan koperasi untuk mengatasi kesulitan di dalam penggunaan koperasi dan informasi yang mendukung di dalam koperasi. Di dalam melakukan proses peminjaman sering mengalami keterlambatan pembayaran koperasi sehingga membuat nilai penunggakan semakin besar dikarenakan masyarakat di daerah memiliki kesibukan di dalam usaha sehingga lupa melakukan pembayaran. Oleh karena itu diperlukan suatu sistem yang dapat membantu masyarakat di daerah kabanjahe.

CU .Bahagia merupakan suatu koperasi yang memilki banyak nasabah yang terleta di daerah kabanjahe. Di dalam menerapkan sistem CRM memiliki petugas khusus yang mengelolah pelanggan. Yang menjadi dampak terhadap $\mathrm{CU}$ adalah bagaimana meningkatkanloyalitas merupakan hal yang sangat menarik untuk dikaji lebih lanjut.

Untuk itu penelitian ini bertujuan untuk mengeahui dan menjelaskan penerapan strategi CRM yang diterapkan CU. Bahagia sebagai upaya untuk meningkatkan loyalitas nasabah.

Saat teknologi semakin maju sampaia sekarang ini, sekurang - kurangnya semua bidang yang ada sudah menggunakan teknik - teknik pembaharuan dari IT (Ilmu Teknologi). Itu disebabkan karena perkembangan IT sekarang sudah banyak digunakan untuk menolong kegiatan dari kalangan masyarakat.dimana dapat membuat suatu pekerjaan semakin lebih murah, tepat sasaran, dan mendapatkan suatu hasil yang memuaskan untuk kalangan masyarakat. Pada sistem yang dibangun ini akan membangun masyarakat di dalam mempermudah kalangan masyarakat di kaanjahe untuk melakukan kegiatan transaksi terhadap CU. Dimana masyarakat sekitar dapat menerima notifikasi pembayaran 3 hari sebelum melakukan pembayaran dan info - info yang terbaru yang menguntungkan pihak anggota koperasi.

\section{METODOLOGI}

CRM dengan menggunakan model regreasi linear dapat membantu di dalam proses peningkatan hubungan timbal balik antar karyawan dengan respon organisasi di dalam suatu instansi pemasaran internal. sehingga dengan model tersebut bisa meningkatkan hubungan yang lebih baik lagi oleh seorang manager dan pemilik bank [3].

Customer relation management menggunakan Scorecard dapat membantu di dalam proses pengukuran kepuasan terhadap pelanggan di kantin FASILKOM UNSRI. bahwa pada perspektif kinerja penjual memiliki suatu dampak yang begitu besar dibanding dengan perspektif proses, pelanggan, dan juga infrastruktur [4].

sebuah data yang besar dibutuhkan sebuah arsitektur di dalam pemasaran karya tulis.CRM yang dapat membantu didalam mengeksploitasi data yang terbaru dengan memperkenalkan arsitektur CRM yaitu arsitektur Adaptasi baru [5].

Di dalam menjalin hubungan terhadap pelanggan di dalam lingkungan Cloud dibutuhkan sebuah CRM salesforce. adapun CRM salesforce ini digunakan agar dapat mengawasi bagaimana komunikasi antara pelanggan dan yang di prospek, 
sehinggan dapat mencari informasi yang diidentifikasi. untuk membantu CRM tersebut dibutuhkan tim untuk menjalin kerjasama baik komunikasi jarak jauh dan tidak.CRM salesforce juga mengumpulkan pengalaman dari jaringan online, melacak pengukuran penting, dan menyampaikan melalui email, telepon, sosial, dan berbagai saluran agar dapat menganstisipasi apa yang menjadi keinginan dari pelanggan [6].

Model analisis tentang CRM sosial yang dilakukan oleh Institut Pendidikan Tinggi Malaysia adalah bagaimana cara menunjukkan masalah yang perlu diselesaikan dan tindakan yang harus diambil segera di dalam menentukan kepuasan pelanggan, loyalitas dan reputasi yang baik.adapun cara yang dilakukan oleh IHL adalh denga melakukan komunkasi yang baik dengan pelanggan secara lebih aktif sehingga dapat mempertahankan apa yang diharapkan oleh Institut Pendidikan Tinggi Malaysia [7]

klasifikasi layanan yang luas dengan menggunakan CRM dapat membantu di dala pegembangan sebuah literatur yang berhubungan dengan topik dan dapat juga diguanakn sebagai referensi, evaluasi, dan pemecahan masalah yang ada kaitannya terhadap CRM Sosial. Dan CRM sosial in juga memiliki dampak terhadap industri didalam integrasi industri dan juga informasi di bidang pendidikan yang menghasilkan sebuah bentuk pelayana yang searah dengan keinginan pelanggan[8].

karakter dan kondisi dalam perangkat memiliki nilai besar dalam mendapatkan hasil yang diinginkan. mengautentikasi file dari mencari file yang diperlukan untuk memiliki aplikasi manajemen hubungan pelanggan yang baik. Sehingga pelanggan dapat mudah melakukan suat pencarian yang lebih baik unutk keperuan dari pelanggan [9]

Customer Relation Management merupakan bagaimana cara melakukan hubungan yang silang antara anggota dan perusahaan agar mempererat kesatuan di dalam kebutuhan yang diharapkan sehingga menjadi member. Customer Relationship Management (CRM) merupakan strategi pemasaran yang membangun relasi yang erat antara perusahaan dengan para membernya. Perusahaan dapat memanjakan member dan mengikatnya dalam sebuah persahabatan jika telah mengetahui kebutuhan dan harapan dari member tersebut[10]

Koperasi juga memiliki sebuah fungsi yaitu membangun dan meningkatkan potensi ekonomi para anggota dan masyarakat serta meningkatkan kualitas hidup perekonomian anggotanya dan juga masyarakat sekitarnya [2].

Sistem CRM yang dibuat melakukan sebuah kegaiatan jual dan beli yang telah dilakukan setiap hari di dalam bisnis yang dilakukan. dengan menggunakan sebuah metode RAD dapat memenuhi apa yang menjadi keinginan oleh pelanggan dengan metode yang dilakukan lebih kencang dan mempermudah pelaku bisnis di dalam menjalankan bisnisnya[11]

Untuk membuat pelanggan semakin mendekat diperlukan sebuah CRM ( Customer Relayion Management) yang akan memenuhi apa yang akan diinginkan oleh pelanggan.Oleh karena itu perusahaan harus memiliki cara ataupun teknik untuk bersaing lebih unggul untuk menyelesaikan apa yang menjadi masalh oleh pelanggan dengan menggunakan teknin CRM ( Customer Relation Management) yang dibuat [13]

Customer Relation Management adalah salah satu bisnis yang bisa membuat penempatan dari user sebagai proses yang utama, di dalam melakuakn tindakan, dan budaya [14].

CRM secara garis besarnya merupakan sebuah teknik memberi bantuan menggunakan Jejaring Sosial di bidang CRM yang berguna untuk melayani, dan mempertahankan pelanggan, salah satu contoh aplikasi proses penerimaan di sebuah universitas. CRM sosial ini ditujukan untuk memilih dan calon pelanggan yang dalam hal ini adalah kandidat siswa yang tepat. Berdasarkan informasi dari akun jejaring sosial[12]

Customer Relation Management sangat memiliki dampak yang sangat baik bagi pelanggan tentang keinginannya di dalam komitmen pelanggan. di dalam itu diperlukan sebuah metode yang berkaitan dengan kemampuan di dalam melakukan tugas mejadi seseorang yang memiliki sifat yang simpatik dari Petugas EF Samarinda dan Sistem IT Pembayaran Di EF Samarinda[14]

Customer Relationship Management secara tersusun di dalam melakukan proses penyimpanan dari file pelanggan, pada aplikasi Fashioncard yang studi kasusnya dilakukan di bandung sport.aplikasi CRM ini dilakukan agar memiliki kemajuan terhadap komitmen dari pelanggan dan ini sudah dilakukan dengan mengggunakan aplikasi tersebut memiliki persentase $25 \%$ dari seluruh penjualan yang dilakukan dalam sebulan.[13]

Pada CRM yang dibuat dengan menggunakan website dapat melakukan bentuk layanan yang terbaik terhdap pelanggan. adapun yang dilakuan di dalam mempertahankan jumlah 
dari pelanggan maka melalui sebuah website yang dibangun dapat memberikan sebuah keterangan yang sangat pasti terhadap orang yang datang / pelanggan yang baru dan memiliki tingkat penambahan pelanggan serta penjualan terhadap buku dan bisnisnya.[12]

Rencana di dalam melakukan sebuah bisnis serta memanfaat kan perkembangan dari pada IT ( Informatika Technology) pada instansi secara menyeluruh, bisa diharapkan, dan terpadu berdasarkan dari sisi pelanggan, dengan begitu semua proses dan interaksi saling membantu mempertahankan dan mengembangkan hubungan yang bermanfaat adalah bagian CRM .Oleh karena itu diperlukan suatu strategi yang lebih baik dengan cara implementasikan suatu produk teknologi informasi yang dapat membantu usaha ini menjadi lebih efektif dalam meningkatkan layanan marketing dan customer support serta dapat menunjang pengambilan keputusan bagi perusahaan. PT. Matahari Dept. Store Menado Town Square memiliki sebuah kelebihan dalam memajukan sebuah informasi dengan membuat sebuah CRM (Customer RelationshipManagement) agar membuat sebuah prototype skema penugasan pelanggan sebagai proses utama dari instansi.[15]

Tujuan penelitian ini adalah untuk membuat suatu deskripsi atau gambaran tentag penerapan CRM yang diterapkan oleh CU.Bahagia sebagai upaya di dalam meningkatkan loyalitas dari nasabah.

Adapun langkah - langkah di dalam menganalisis data dalam penelitian ini adalah:

1. Mendiskripsikan penerapan Customer Relationship Management (CRM) yang dimanfaatkan oleh CU untuk menghimpun serta menganalisa informasi dari pelanggan, beserta infrastruktur teknologi yang mendukung program Customer Relationship Management (CRM).

2. Mendiskripsikan program pelanggan yang dibuat oleh CU dalan mendukung penerapan Customer Relationship Management (CRM).

3. Menganalisa penerapan Customer Relationship Management (CRM) pada CU dan upaya perusahaan dalam mewujudkan keberhasilan penerapan Customer Relationship Management (CRM) berdasarkan pada kunci keberhasilannya melalui komitmen pada manajemen puncak, tidak hanya berfokus pada teknologi, adanya keterlibatan pelanggan, otomatisasi sesuai kebutuhan, dan mitra bisnis.

4. Mendiskripsikan target dan realisasi di dalam tagihan yang dibuat oleh perusahaan selama penerapan Customer Relationship Management (CRM) selama periode tertentu.
5. Mendiskripsikan hambatan yang dihadapi oleh CU dalam penerapan Customer Relationship Management (CRM).

6. Mengambil kesimpulan mengenai penerapan Customer Relationship Management (CRM) sebagai upaya untuk meningkatkan loyalitas pelanggan

\section{HASIL DAN PEMBAHASAN}

Pada bab ini menunjukkan tampilan flowchart terhadap system yang akan dibangun, adapun flowchart yang telah dibangun dapat dilihat pada gambar 1 :

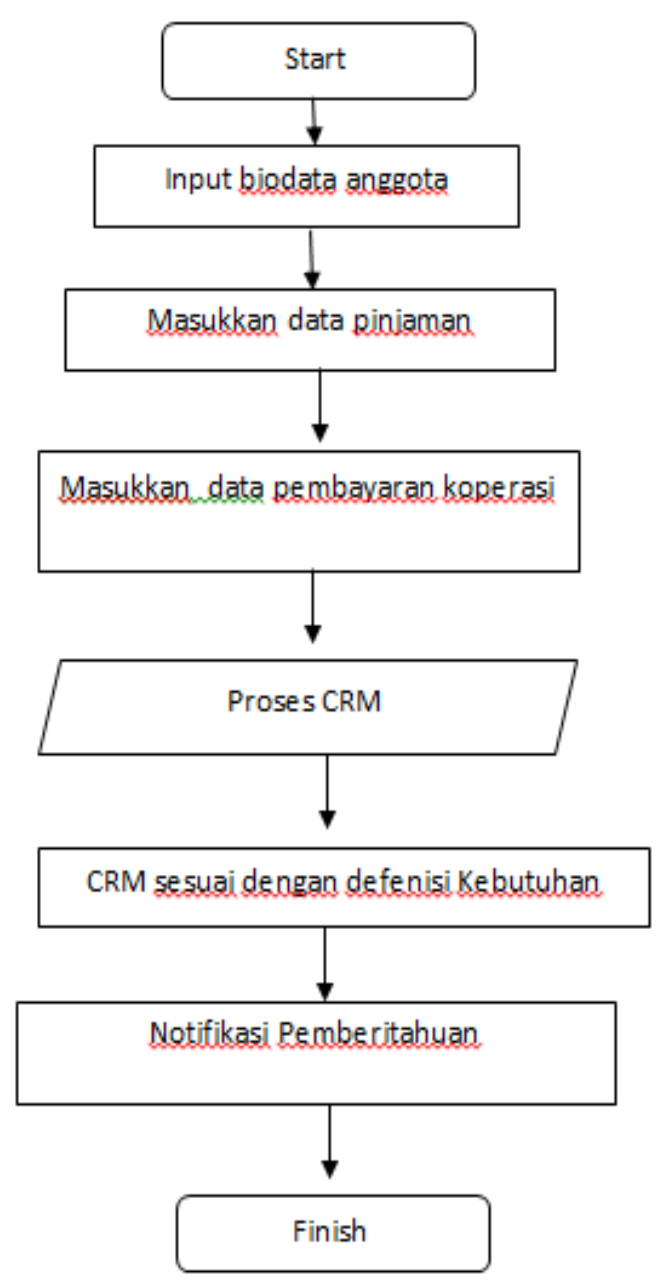

Gambar 1. Flowchart Aplikasi CRM

\section{A. Tampilan Utama Website}

Pada gambar 2 dapat dilihat bahwa tampilan utama ketika membuka sistem . dimana pada tampilan ini merupakan tampilan user yang hanya bisa melihat tentang pemberitahuan tentang 
kegiatan yang dilakukan oleh CU. Bahagia. dimana tampilan utama ini bisa melakukan our service terhadap anggotan. Dimana ourservice yang dilakukan berupa simpanan, pinjaman, layanan khusus, dan kantor pelayanan.

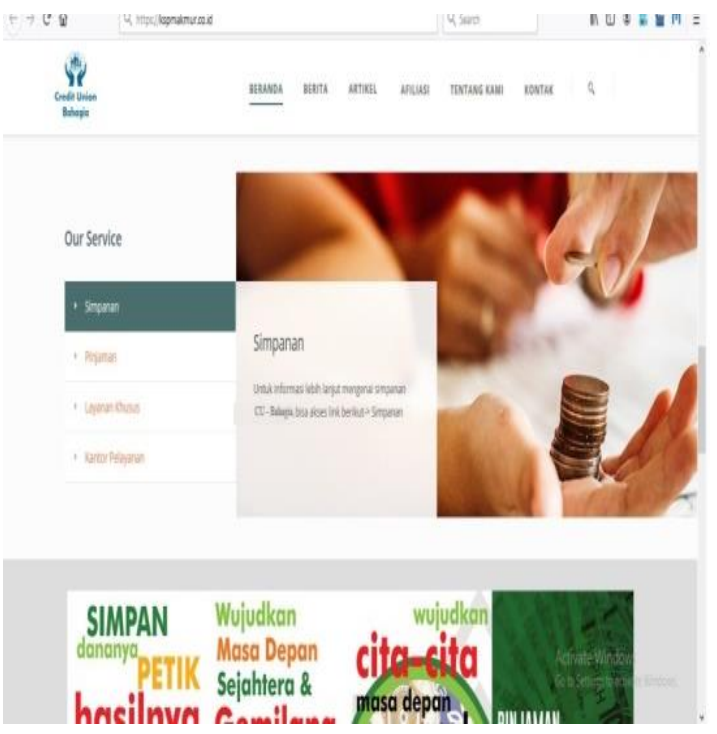

Gambar 2. Tampilan Utama

\section{B. Tampilan Dashboard Administrator}

Pada gambar 3 dapat dilihat bahwa administrator tersebut terutama harus mengisi user name dan password agar dapat melakukan kegiatan yang bisa dlakukan oleh admin. Karena di sistem yang dibangun ini yang memiliki hak akses full itu diberikan kepada admin. Admin juga bisa merubah paswwordnya menjadi password yang baru.

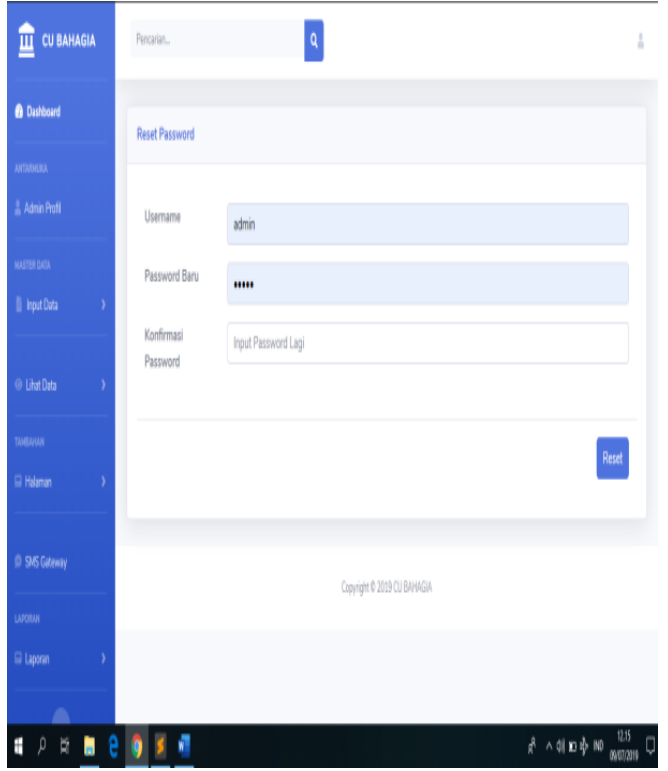

Gambar 3 . Tampilan Admin

\section{Tampilan Inputan data nasabah pada halaman admin}

Gambar 4 merupakan tampilan di dalam penginputan data nasabah baru yang ingin mendaftar sebagai anggota. Pada saat mendaftar harus memiliki KTP dikarenakan KTP merupakan primarykey di dalam sistem yang dibuat. Adapun pada Gambar 4 yang menjadi inputan terhdap biodata adalah NIK, nama anggota, tempat/tanggal lahir, jenis kelamin, pekerjaan, alamat, notelepon dan no hp. di dalam sistem dibutuhkan nomor telepon agar pihak nasabah dapat melakukan interaksi terhadap admin di dalam proses penyampaikan tentang berita - berita yang terbaru ataupun kegiatan - kegiatan yang dilakukan oleh CU.Bahagia serta dapat membanu di dalam proses pemberitahuan notifikasi tentang pembayaran / iuran pembayaran nasabah baik jumlahnya dan juga tangal berapa pembayaran iuran terhadap CU.Bahagia.

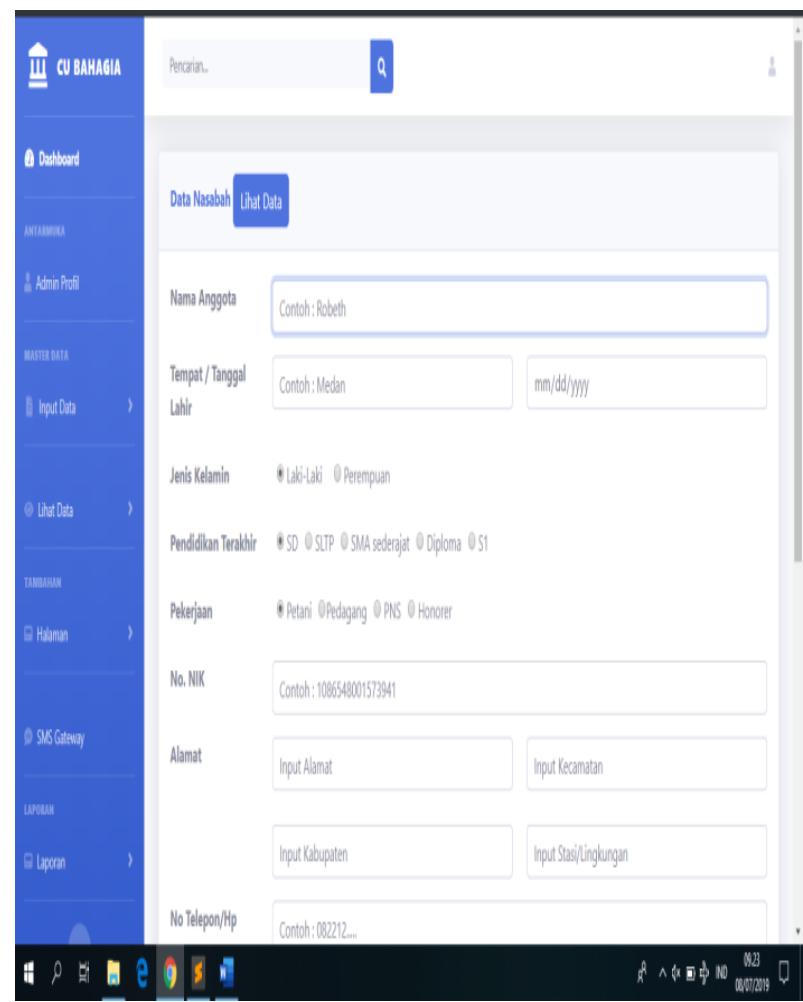

Gambar 4. Inputan Data Nasabah pada Admin

\section{Tampilan data nasabah yang sudah diinput}

Pada gambar 5 merupakan data nasabah yang sudah diinput, dimana data tersebut merupakan data buku ataupun biodata yang telah direkapitulasi di dalam sistem. 


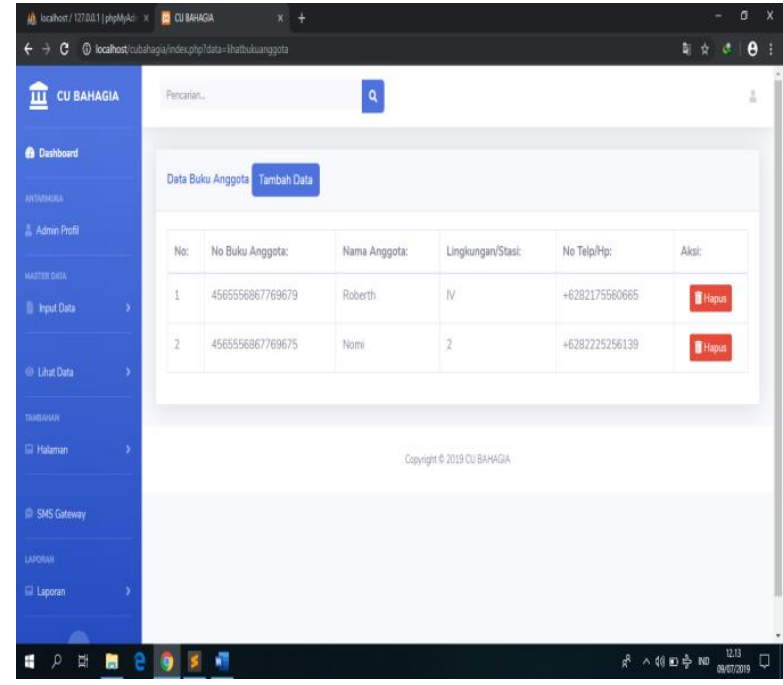

Gambar 5. Data Nasabah Yang Diinput

\section{E. Tamnilan untuk nengiriman nesan pada Persentase AplikasiCRM}

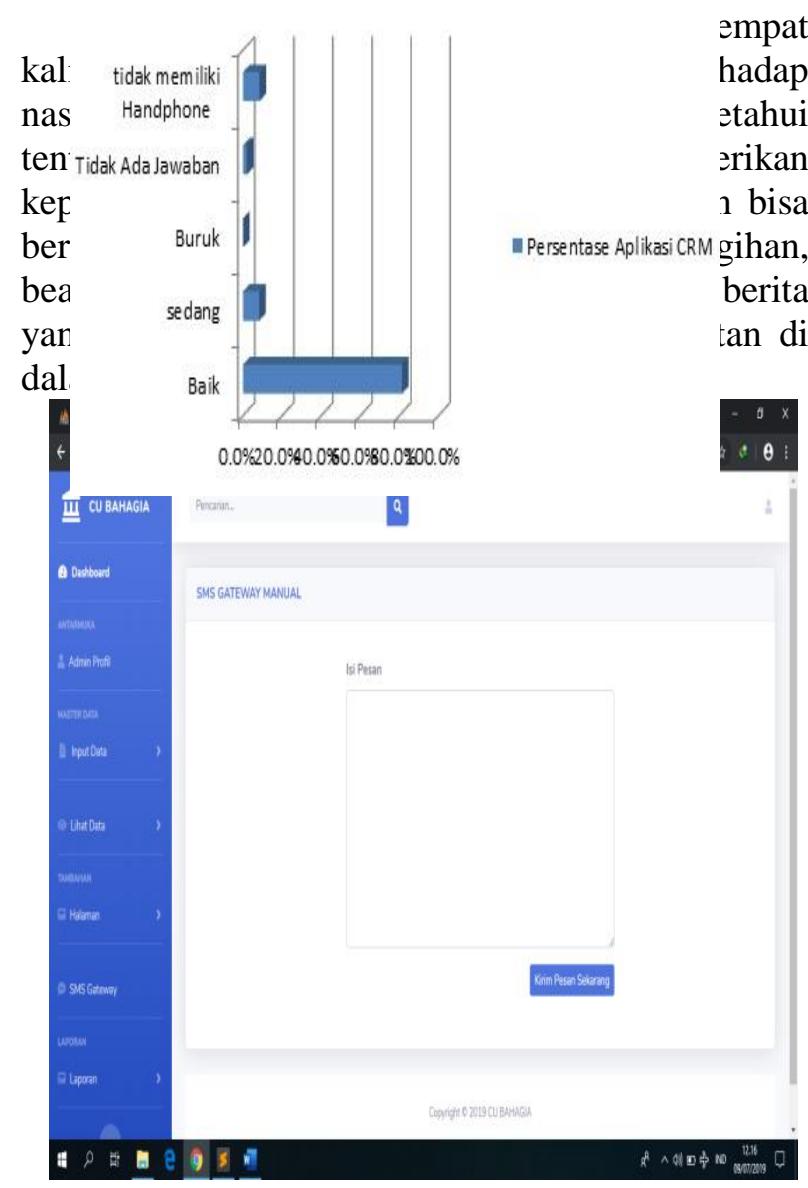

Gambar 6. Tempat Pengisian Pesan Terhadap Nasabah
F. Tampilan yang diterima nasabah dari handphone

Setelah diisi apa yang akan dikirim kepada nasabah maka akan masuk ke dalam handphone sms dari CU tersebut. Pada gambar 7 merupakan notifikasi terhadap anggota dimana notifikasi memberitahukan bahwa pembayaran tagihan jatuh tempo ditanggal berapa dan total biaya tagihan yang akan dibayar kepada CU. Bahagia.

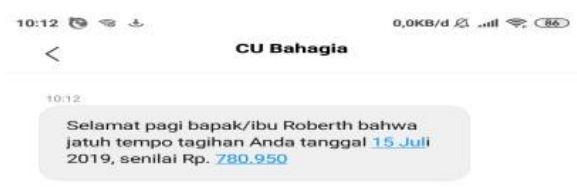

Gambar 7. SMS yang diterima Nasabah

\section{G. Persentase pengguna Sistem CRM yang dibangun}

Adapun untuk membuktikan bahwa sistem CRM tersebut berjalan lancar perlu dibuat sebuah pertanyaan kepada pelanggan mengenai bagaimanakah sistem yang dibuat. Pada gambar 8 dan gambar 9 menunjukan persentase tanggapan dari nasabah mengenai penggunaan sistem tersebut. Adapun diagram tersebut dibuat melalui diagram lingkaran pada gambar 8 dan gambar 9 . Diagram tersebut dapat membantu melihat persentase tentang sistem CRM (Customer Relation Management) yang dibuat,bagaimana sistem tersebut dapat membantu di dalam proses kinerja dari sistem yang telah dibangun yang dapat mempermudah bagi nasabah koperasi tersebut.

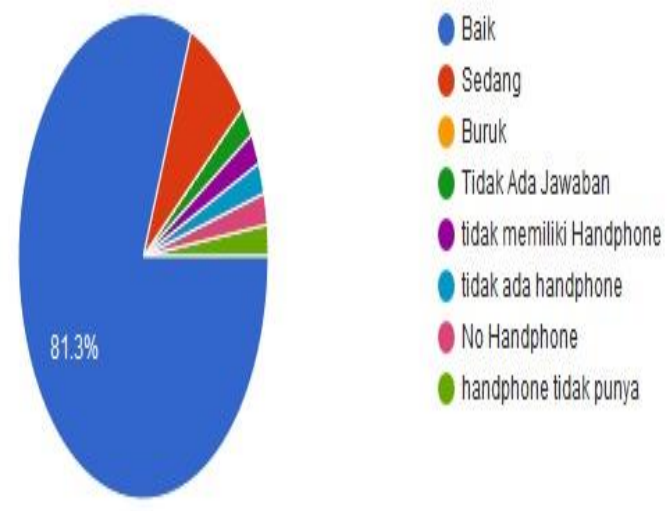

Gambar 8. Diagram Lingkaran Persentase 


\section{Persentase Aplikasi CRM}

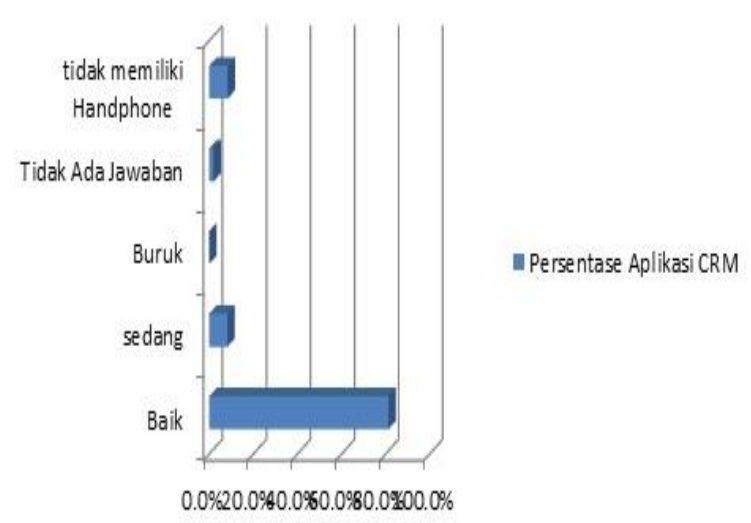

\section{Gambar 9. Diagram Batang Persentase}

Berdasarkan gambar diagram batang dan diagram lingkaran diatas dapat diambil kesimpulan tentang perbandingan sistem CRM yang dibangun dari pendapat nasabah yangsudah menjadi anggota di dalam koperasi CU. Bahagia. Adapun yang menjadi pendapat anggota koperasi tentang sistem yang dibuat adalah baik, sedang,buruk, tidak ada jawaban, dan tidak memiliki handphone. Dari beberapa jenis tanggapan tersebut bahwa $81,3 \%$ nasabah telah menyatakan bahwa sistem CRM (Customer Relation Management ) tersebut merupakan sangat baik digunakan oleh setiap anggota koperasi di daerah kabanjahe, setelah itu ada lagi memberi tanggapan bahwa 8,3\% menyatakan bahwa sistem tersebut kurang baik dikarenakan desain pada tampilan sistem CRm yang dibangun tampilan yang tidak menarik, 0\% menyatakan bahwa sistem CRM yang dibangun tidak punya masalah. Nasabah berikutnya memberikan tanggapan bahwa sebesar 2\% mengatakan tidak ada masalah terhadap sistem CRM yang telah dibangun, dan $8,4 \%$ menyatakan nasabah menyatakan bahwa nasabah tersebut gaiamna bentuk sistem yang dibangun dan nasabah tidak memiliki ponsel untuk mendapatkan hasil baiman output dari sistem yang telah dibangun sehingga mereka tidak bisa memberi tanggapan. Berdasarkan diagfram diatas dapat dinyatakan bahwa sistem CRM ini merupakan sistemnya berjalan dengan baik dan dibutuhkan oleh nasabah.

\section{SIMPULAN}

Dari uraian singkat diatas, beberapa hal yang bisa menjadi kesimpulan

1. Aplikasi Customer Relation Management ini dapat mempermudah di dalam proses transaksi antara CU dengan nasabah.
2. CRM yang digunakan di dalam sistem ini adalah sebuah notifikasi yang diteruiam oeh Nasabah di daerah berastagi sehingga dengan mudah menerima berita - berita atapun event event yang akan dilaksanakan melalui notifikasi yang diterima melalui ponsel nasabah dan juga notifikasi untuk pembayaran tagihan dari nasabah.

3. Bahwa notifikasi diberikan 3 hari sebelum waktu tempo atau event yang dilakukan.

\section{UCAPAN TERIMA KASIH}

saya sebagai peneliti mengucapkan terima kasih kepada semua yang terkait di dalam penelitian ini sehingga penelitian ini berjalan dengan baik dan peneliti juga berterima kasih kepada CU. Bahagia yang telah membantu peneliti sebagai tempat untuk penelitian ini.

\section{REFERENSI}

[1] N. Karna, I. Supriana, and U. Maulidevi, "Social CRM using web mining," in 2014 International Conference on Information Technology Systems and Innovation (ICITSI), Bandung, Indonesia, 2014, pp. 264-268.

[2] C. F. Sitepu and H. Hasyim, "PERKEMBANGAN EKONOMI KOPERASI di INDONESIA," NIAGAWAN, vol. 7, no. 2, Jul. 2018.

[3] C. Therasa, C. V. Banu, R. Gayathri, S. Gopalakrishnan, and S. Manikandan, "Linear regression model fit for internal marketing and customer relationship management," in 2017 International Conference on Intelligent Sustainable Systems (ICISS), Palladam, 2017, pp. 927-932.

[4] A. Ibrahim, A. Pratiwi, D. I. Meytri, Madri, M. A. Kurniawan, and N. Yuniarti, "Measuring Customer Satisfaction Using CRM Scorecard in Canteen FASILKOM UNSRI," in 2018 International Conference on Electrical Engineering and Computer Science (ICECOS), Pangkal Pinang, 2018, pp. 403408.

[5] A. Daif, F. Eljamiy, M. Azzouazi, and A. Marzak, "Review current CRM architectures and introducing new adapted architecture to Big Data," in 2015 International Conference on Computing, Communication and Security (ICCCS), Pamplemousses, 2015, pp. 1-7.

[6] A. Manchar and A. Chouhan, "Salesforce CRM: A new way of managing customer 
relationship in cloud environment," in 2017 Second International Conference on Electrical, Computer and Communication Technologies (ICECCT), Coimbatore, 2017, pp. 1-4.

[7] A. Hamid et al., "Social CRM Analytics Model on Malaysian Institutes of Higher Learning (IHLs)," in 2018 3rd Technology Innovation Management and Engineering Science International Conference (TIMESiCON), Bangkok, Thailand, 2018, pp. 1-5.

[8] G. M. Barata, J. A. Viana, O. Reinhold, F. Lobato, and R. Alt, "Social CRM in Digital Marketing Agencies: An Extensive Classification of Services," in 2018 IEEE/WIC/ACM International Conference on Web Intelligence (WI), Santiago, 2018, pp. 750-753.

[9] A. Ibrahim, Ermatita, Saparudin, and Z. Adetya, "Analysis of weakness of data validation from social CRM," in 2017 International Conference on Data and Software Engineering (ICoDSE), Palembang, 2017, pp. 1-5.

[10]E. Siswanto and A. W. Katili, "Implementation of decision support system for campus promotion management using fuzzy multiple analytic decision making (FMADM) method (Case study: Universitas multimedia nusantara)," in 2017 4th International Conference on New Media Studies (CONMEDIA), Yogyakarta, Indonesia, 2017, pp. 75-80.
[11]A. Fauzi and E. Harli, "Peningkatan Kualitas Pelayanan Melalui CRM dengan Metode RAD," J. RESTI Rekayasa Sist. Dan Teknol. Inf., vol. 1, no. 1, pp. 76-81, Aug. 2017.

[12]E. Utami, "PENERAPAN CUSTOMER RELATIONSHIP MANAGEMENT UNTUK MERANCANG FITUR APLIKASI PENJUALAN BUKU ONLINE," vol. 6 , no. 1 , p. 9, 2013.

[13]A. O. Carissa, A. Fauzi, and S. Kumadji, "PENERAPAN

CUSTOMER

RELATIONSHIP MANAGEMENT (CRM) SEBAGAI UPAYA UNTUK MENINGKATKAN

LOYALITAS PELANGGAN," p. 11.

[14]K. F. Fardhani, I. Rachmawati, and F. S. Prabowo, "PENGARUH CUSTOMER RELATIONSHIP MANAGEMENT (CRM) TERHADAP LOYALITAS PELANGGAN ENGLISH FIRST SAMARINDA," p. 4.

[15]R. E. Kalalo, "CUSTOMER RELATIONSHIP MANAGEMENT DAN KUALITAS PELAYANAN PENGARUHNYA TERHADAP LOYALITAS KONSUMEN PT. MATAHARI DEPT. STORE, MANADO," p. 9, 2013. 